\title{
Effectiveness of Feeding System for Enhanced Product Quality in Sand Casting Industries
}

\author{
I.Rajkumar, N.Rajini
}

\begin{abstract}
This review article deals with the importance of process parameters and the recent developments in modern tool technology in the success of smart productivity for casting process of all types. Various influencing factors such as design, location and the number of gating on feeding mechanism were discussed vis-a-vis casting defects. The review revealed reduction in the defects such as air bubbles, blow holes, shrinkage defects and mechanical properties of the casting parts through selection of an optimum feeding design. Variations in fillet radius and thickness on the feeding system were found to be the factors affecting the location of the hot spot. Accordingly, the mobility of the hot spot was controlled by geometrical modifications in the feeding system. In addition, the formation of pinholes and solidification defects could be reduced through a proper arrangement of the feeding system. The rapid growth in implementing simulation techniques in the casting process can assist the enhancement of yield with minimum production cost. This article provides a data base relating to the merits and demerits of various factors and material systems with their industrial applications for enabling further research in the casting process.
\end{abstract}

Keywords : Casting, , hot spot, shrinkage, simulation, yield

\section{INTRODUCTION}

$\mathrm{D}_{\mathrm{e}}$ espite the metal casting process being one of the oldest processes in the fabrication of metal components, advancements in research are still required for obtaining quality products through cost effective ideas [1]. In particular, problems like quality control, low production, energy efficiency, reduction in material consumption and the impact of environmental production are frequently seen in modern casting industries. In recent days, extensive research has been done in the aspect of optimization on the casting process to identify the parameters affecting quality measures [2-3]. Accordingly, factors such as mould material, poring basin, runner and gating system have been found to have a significant effect on product quality in the casting process [4-5]. Hence, it is mandatory to create a database with key findings seen in published articles with respect to casting parameters on quality measures that would be useful for small scale casting industries.

A recent survey on casting market reports that the countries like China, US and India have made substantial improvements in the production of the casting components. In particular, Asian counties such as China and India are in the forefront in

Revised Manuscript Received on December 05, 2019.

* Correspondence Author

I.Rakumar*, Department of Mechanical Engineering Kalasalinagm Academy of Research and Education, Krishnankoil, Virudhunagar, Tamil Nadu, India. Email: irajkumarilango@gmail.com

N.Rajini, Department of Mechanical Engineering, Kalasalinagm Academy of Research and Education, Krishnankoil, Virudhunagar, Tamil Nadu, India. Email: rajiniklu@ gmail.com this context [6]. This was possible due to the existence of atmospheric temperature suitable for the casting process. Indian casting industries are actively involved in the development of casting products in various applications. A suitable process has to be selected from among several processes based on the requirements of the product and the area of its use. Hence, every industry is keen on selecting the casting processes that would answer the mandatory requirements with minimal production cost [7]. There are various factors that need consideration before the selection of the casting process. Mechanical properties like hardness and tensile strength have been identified as important criteria for any casting part before having put into use [8]. It has been proved that sand casting and pressure die casting parts can offer enhanced mechanical properties as confirmed from the earlier published work [9-10].

Currently, there are many new technologies under implementation in casting industries. However, most of the small scale casting industries are struggling to produce quality products is an economical way for different materials. Some review articles have been published relating the casting process in the aspect of the role of simulation software by considering the various influencing factors for different applications [11-12]. The various types of casting defects are shown in Fig.1 At the same time, there has been no considerable exploration of the design of the feeding system on the performance of casting products seen in the research articles published so for. Hence, this review article addresses the significance and applicability of a feeding system in the casting process for providing the significant information that can help achievement of mass production with minimum time consumption.

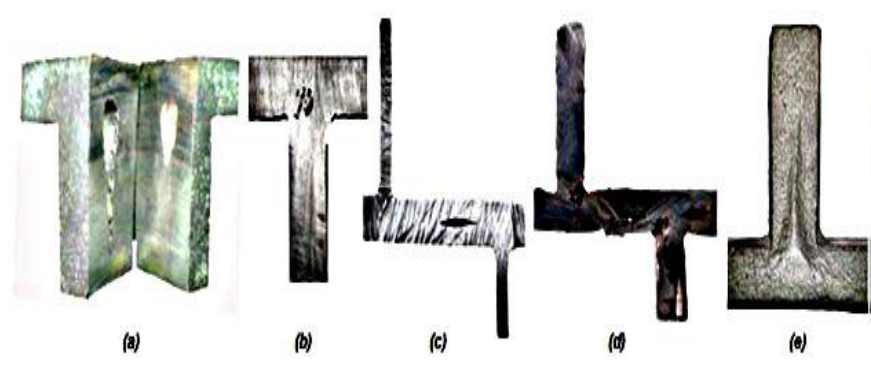

Fig. 1. (a) shrinkage cavity, (b) shrinkage porosity, (c) canter line shrinkage, (d) corner shrinkage and (e) surface sink. [44].

\section{SAND CASTING PROCESS}

Sand casting is one of the most widely used casting methods followed by small scale casting manufacturers due to its advantages like low initial investment cost, versatility in casting design and recyclable mould sand. It is also eminently suitable for various 
metals and alloys like nickel, copper and iron that are known for high melting temperature. The process starts with the molten metal poured into a sand mould and allowing it to solidify at room temperature. The sand mould is then broken and the final finished casting product is removed. Fig. 2 shows the various steps and components involved in the sand casting process. Previous research work shows defects such as improper pattern, wrong gating system, poor of sand quality, molten metal composition affecting the performance of the sand cast products [13-14].

Fig. 2 Steps and components of sand casting process.

Further, parameters like the grain size and bonding material are also found to play a significant role in achieving a quality casting product [15-16]. However, the design of the feeding system is identified as the key factor for producing good quality parts with the least cost. However, the selection of an effective feeding option is no easy job due to variations from component to component, requiring an extensive trial and error process [17].

\section{A. Significance of feeding system in casting process}

It is well a known fact that the efforts of all the small scale sand casting industries are towards achieving quality products at a low cost. Consideration of the design of the gating system is inevitable for achieving success in this task [18]. Accordingly, industries are trying with 'Right the First Time' approach to minimize time consumption. However, attainment of this in the real time sand casting process is no easy task. Hence, lots of trial and error methods are still being undertaken by small scale industries.



Fig.3. Elements of a typical gating system [20].

On the other hand, large scale industries have started implementing the simulation techniques which are found to be less time consuming in the selection of the optimum parameters for appropriate condition. In the forthcoming section, various designs of gating systems are discussed with the support of experimental and simulation results [19]. Fig.3 shows the casting components with the experimental set up of a runner, liquid basin, sprue, well runners, gates and slag



traps. Factors like the shape and the size of the feeder and feeder neck, location of the feeder, insulating sleeves and covers, fins and chills have been taken into account in designing the feeder system to avoid shrinkage defects at different regions [20]. At the same time, a perfect gating system can ensure smooth, complete and uniform filling with less time enabling detection and elimination of many defects

\section{B. Based on component orientation of gating system}

The main purpose of introducing the gating system is to connect a number of casting cavities for achieving higher productivity [20]. On the other hand, in the horizontal feeding system, the symmetrical arrangement of gating was found more suitable for a thick wall casting, exhibiting uniform temperature distribution, flow and air entrainment. In addition, the simulation results show the possibility of a $30 \%$ reduction in rejection arising from feeding system related defects. Researchers have also analyzed the defects after the machining on plate at various thicknesses 5 and $10 \mathrm{~mm}$ components using ultrasonic test results [21] and found no pin holes or gas porosity. The results have exhibited achievements of a good surface finish of the product using a dry sand mould. On the other hand, the percentage of porosity was found to be low in the case of air-set sand mould compared to other types of sand mould. Further, air-set sand moulds produced class thin-walled sand cast components of below $1.5 \mathrm{~mm}$ thickness with the use of the combined effect of additive layer manufacturing and casting simulation techniques [22].

\section{Based on Gating and Riser Location}

A research work was carried out on the runner design (main and side runner) in obtaining defect free quality product. Modification in the straight runner as a tapered runner and a reduction in oxide layers were found. The straight runner flow allows air entrainment and produces uneven filling shown in Fig.4 Increased filling ratio and uniform metal entry were observed in the tapered runner flow. A change in the fillet radius of tapered runner was done automatically using design optimization with MAGMASOFT. Further, different optimization goals were used for achieving a quality product with minimum production time through control over the various manufacturing parameters like geometric feeder system (location and shape and size of runner, gate, riser) and chills [18]. In one of the works, the gating system design was done for eliminating the oxide layer and sand inclusion that occurred due to the existence of the turbulence flow. Experiments were carried out using two different gating designs, namely, the pressurized gating system (PGS) and the new version gating system (NVGS) for achieving this. Fig.5 shows the defects in the casting were analysed with the support of a simulator software. Results indicate melt velocity as one of the critical factors leading to the formation of oxide layer based on the type of flow. Accordingly, casting products formed by NVGS design do not exhibit any oxide layers and sand inclusion defects. This was eventually confirmed from the final inspection using a scanning electron microscope and Energy Dispersive Spectroscopy analysis [23]. 




Fig. 4. Different runner design and its defects (a) straight runner, (b) Oxide defects, and (c) optimized taped runner [19]

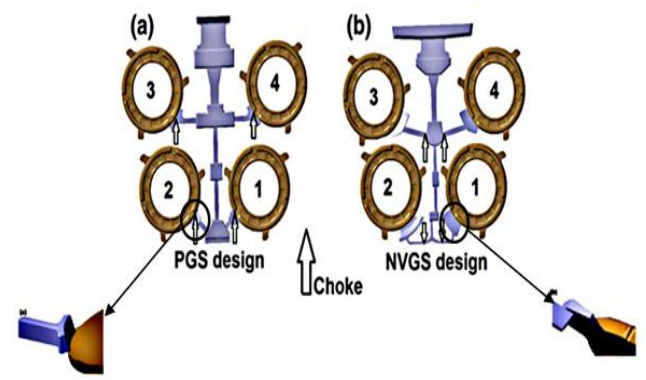

Fig. 5. Layout of (a) PGS design with lap gate and (b) NVGS design with edge gate (Arrow shows magnified lap and edge gate) [23]

Recently, the importance of reducing hot spots through an appropriate design of feeding system with respect to directional solidification was analyzed [24]. Literature shows the ability of the optimized feeder placement to enhance casting yield up to $15 \%$ with the outcome of defect free casting and with a minimum number of experiments. Results of analysis obtained from the simulation of Auto Cast-X software (Fig.6) help visualizing the progress of hot spot, and in turn, exhibit the formation of shrinkage defects. Moreover, a perfect design of feeding can help attainment of guiding solidification with a decrease in failure due to spot solidification and incomplete filling [25]. In another research, Results showed the four-cavity mould as effective more than the three-cavity system, in achieving a quality casting product in both cast parts. The risk of formation of micro-shrinkage could be minimum to with the case of a centre cavity rather than going in for a side cavity. The developed model suggested reduction in cross-sectional area for the first gate to diminish the possibility of air entrapment. The effects of various parameters such as melt superheat, pouring time (velocity), mould surface roughness, gating design, and the mould configuration on the quality casting product could be studied, using this model [26].
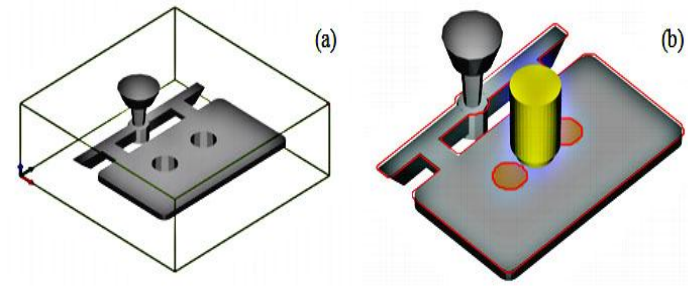

Fig. 6 Cover plate simulation with use of AutoCAST-X, (a) Identifying the shape complexity of the part (b) Feeder location at hot spot [25].
In another study, a casting valve-type product was analysed using the numerical simulation technique [26]. Based on the results, the performance of the casting part in the aspect of solidification sequence, filling behaviour and thermal stress distribution were discussed and the reasons for the formation of defects such as cold shut and shrinkage were also predicted. The results suggested a single-gating system as an alternative to the double gating system for the valve -type product. The need for chills for the same product was also discussed through reduction in defects with enhanced quality product, the usage of multi cavity with different feeding systems was investigated for the brake disk in automobile applications by researchers [27]. Three different layouts were proposed using a modified design with respect to geometric parameters shown in Fig.7. Accordingly, changes like dimensions of runner, curved of runner, down sprue point of connection runner, cross section of down sprue dimensions and dimensions of ingate and position have been proposed in the new layouts for improvements in the quality cast obtained. However, an optimized streamlined feeding system was identified on the bases of the simulation results. Results showed reduction in air entrainment and turbulence flow with minimal material usage which facilitated the enhancement of casting yield from $73 \%$ to $77 \%$ [27-28].

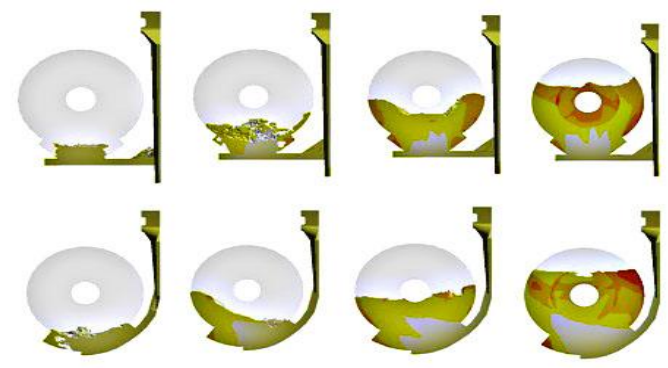

Fig. 7 Various gating design of brake disk filling: conventional (upper) and optimized streamlined gating system (lower) [28].

Different optimization techniques were used for the selection of an appropriate quality system [29]. In this regard, a study explains the importance of gating location using the Genetic Algorithm (GA) optimization technique for the excavator bucket component [30]. Based on the results, the optimum feeding system was seen providing good results with reduced consumption of molten metal with the added benefit of achieving quality casting parts. Parameters like ingate cross sectional area and ingate height were identified as the supporting elements of optimized geometry feeding system for the getting better results compared to the previous processes.

\section{Based on type of Gating System}

In this section, single and multi-gating systems for different applications with the support of some of the reported works are discussed. The metal flow sequence through the multi gating system for different materials was analyzed by Ravi and his associates using a simple experimental setup shown in Fig. 8 The result showed variations in output parameters such as entry of metal flow in gating and sequence of flow and flow rate based on the materials. They have also developed an empirical relation based on the experimental data obtained for the percentage of 
flow rate through the four gates. The results have led the selection of appropriate material for correct gating system from the simulation model various condition as reported by researchers [20]. The same research group have referred to an earlier case of the study of numerical simulation of flow of water and aluminum alloy LM6 through a multi-gate gating system which has been pictorially represented [31]. Results showed increase in the discharge of molten metal 1.7 times that of water. They have analyzed eleven sets of iteration with different gating systems using the end sprue arrangement. Researchers have designed a novel multigate by connecting three gates in various 3D-L junctions with the runner. This design shows the velocity of the stream as equal even with the occurrence of pressure drops. The coefficient of discharge (Cd) for the single (L1 - junction) and multi - gate runner system was also measured. In both cases, the $\mathrm{Cd}$ values were almost the same and followed the fiction loss of $30 \%$ applicable for all the filling system. The filling time for this conduction was 1.43 time longer than friction free condition [32].

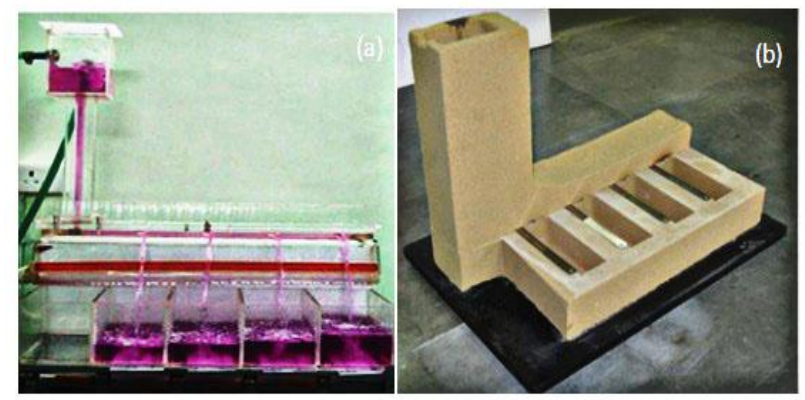

Fig. 8 (a) Water flow experimental setup and Mould assembly for metal pouring [20].

In one of the studies, the filling process on sand casting product of AC4C material was monitored through in-situ process using X-Ray apparatus. Results indicated minor effects from change made in the liquid melt flow based on back pressure of gas in the mould cavity for the pressurized feeding system and sand mould with perfect air permeability [33].

The importance of feed path with respect to the solidification process and generation of hotspot was discussed through the use of a new model called gradient vector method [34]. The results of analysis of this method were compared with those of the other two methods, namely, Modules Vectors Method (MVM) and Level Set Method (LSM). Though, MVM and LVM models exhibited good agreement with the experimental results revealing the hot spot mobility, Gradient Vector Method (GVM) was found to be superior due to the benefits of time saving, yield optimization and suitability for multi junction casting with respect to various boundary conditions [34]. The faster rate of filling system for GVM and other simulation results obtained through LSM. The reduction in wastage of $\mathrm{Co}-\mathrm{Cr}-\mathrm{W}$ alloy for a selected mould design was discussed using ANSYS®FLUENT flow simulation. Results indicated the role played by the variation in the design of gating system and gate location in the casting quality, minimizing the metal wastage, increasing the refilling character and avoid the unfilled errors. The changes in the extension of riser gate fillet radius can facilitate back pressure and, in turn, eliminate unfilling errors also. As a result, a rise in molten metal took place due to the back follow dynamics which trigged the refilling of the unfilled volume and thus wastages of material can be minimized by $11 \%$ [35].

\section{KEY FINDINGS FROM SAND CASTING PROCESS IN VARIOUS ASPECTS}

\section{A. Surface roughness}

$>$ Sand grain fineness and poring temperatures are also being identified as the factors affecting the surface roughness in the sand casting process [16].

$>$ The surface quality was seen as depending mainly on the type of the sand used in the casting process. Accordingly, air-set sand have been found exhibiting better surface finish compared to other sands namely, dry sand and sodium silicate sand [22].

$>$ The type of molten metal flow during mould filling has a major influence on surface quality. Accordingly, the formation of vortex flow leads to the increasing surface roughness which is seen occurring due to the mould erosion. Hence it is important to avoid vortex flow type to obtain the smooth surface finish [36]

\section{B. Geometric modifications}

$>$ The design of a tapered runner and an increasing runner radius can avoid uneven metal entry into the component and eliminate the formation of oxide layers [19].

$>$ Horizontal feeder: It enables getting minimum solidification and air entrainment defects, which are observed via ultrasonic testing of rectangular shaped $\mathrm{X}$ metal casting component [21].

$>$ In four cavity pressure plate application, the major design changes like increasing the poring cup area are known for automatic decreases in metal pressure, reduction in the runner thickness caused change in the flow in turbulence to laminar flow [23].

$>$ Single down spure feeder design can lead to a reduction in cold shut shrinkage and crack formation defects compared to the two down sprue system in the case of steel part valve body [27]

$>$ Proper positioning of chills and risers facilitates uniform distribution of temperature during the solidification process. This can minimize shrinkage defects [37].

$>$ Shrinkage porosity is reduced due to minor changes at outer radius, inner radius, thickness, length, angle and chamber for the L, V and Box shape LM25 component [38].

\section{Numerical Simulation}

$>$ In the case of mass production, uneven metal entry can be minimized through proper selection of the optimum runner design using MAGMASOFT simulation software which is also used for analysis of the filling time and air entrainment [19] in the cast product. The simulation results for different metal castings using the gating system.

$>$ The mobility of hot spot and temperature distribution can be analyzed with the use of Auto-Cast X1 software, which was demonstrated in rectangular wear plate with the effect of varying location of feeder design [21].

Similarly, FLOW Cast software can also be used

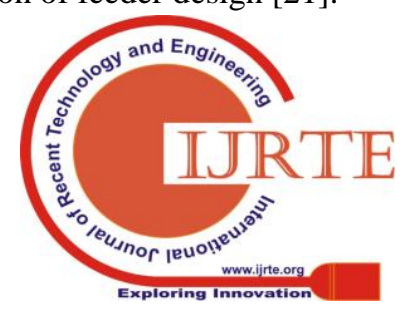


for identifying the hot spot and the solidification process [22]. This simulation results showed good agreement with the experimental results for the application of the engine block.

$>$ MAGMA software was found to be an efficient tool for identifying a suitable gating type which can help reduction in the formation of turbulence flow [23]. Further, factors like mould filling time, velocity of casting, porosity and identification of hot spot can also be simulated using this software [30].

$>$ Solidification sequence, solid fraction time and temperature distribution were analyzed using Flow 3D software for break disc and flywheel application.

$>$ NOVACAST software was used for identifying the volume flow rate and filling time [31] in LM6 cast component.

$>$ The optimum gating design and gating location can be identified using ANSYS FLUENT simulation software which would help to enhance the yield [35].

$>$ ProCast software was used for simulating the heat flux and heat transfer coefficient of the cast component. Use of this software, helps finding good accuracy in simulation result for the heat conduction study in cylindrical casting model [39].

$>$ The dynamic poring method was seen as better than the ProCast simulation results obtained from the top and bottom poring methods. This is a movable gating system which can be positioned at the top of liquid metal surface [40].

$>$ ProCast simulation was carried out on WE54 magnesium alloy with the effect of different riser diameter. Results showed $60 \mathrm{~mm}$ riser diameter with the riser length of $80 \mathrm{~mm}$ length riser as the most suitable [41].

$>$ ProCast software with the simulation of sand casting process. The simulation results, showed the slot gate system exhibiting a better performance than the bottom gating system with respect to solidification and shrinkage porosity [42].

$>$ The simulation result was one of the important aspect of the cast research. Reduction in casting defects like shrinkage porosity, blowhole and pinholes present in the case of contact wheel were found through the selection of a proper optimum feeder design with the help of AutoCast simulation software which leads to the optimum yield of the casting [43].

\section{RESEARCH GAPS AND FUTURE PERSPECTIVE OF METAL CASTING PROCESSES}

A detailed review process, led to the observation of only few research focus on the study of molten metal velocity can leads to minimum the casting defects such as oxide layers, internal cracks, flow marks and porosity. The manufacture of thin wall sand casting product has been found to be limited, requiring further attention towards achieving optimum pouring temperature and riser and gate location. Achievement of this can help getting the common data base with the information on suitable pouring temperature for the corresponding wall thickness.

\section{A. Angle gate}

This can be used for specific applications. Regarding the design, the structure of the angle gate (Refer Fig.9 a) is almost equal to that of the edge gate but this provides a small angle of inclination with respect to horizontal. Normally, this gate is attached to the component at the machined edge to enable filling the hot spot first.

\section{B. Center gate}

The center gating system is appropriate only for the components with a thicker cross section at the center and the extension of center lever. The center gating is simple in construction and can produce a higher yield compared to the previous two gating systems (Fig.9 c). However, the quality of the product is found to be not up-to the expected level of accuracy due to the existence of turbulence and uneven filling. Further, it can be used only in some special cases where the component has the machining surface only at the top face.

\section{Edge gate}

Gating system of this type has a simple structure connected to the component through the front face of the edge gate (Refer Fig.9 e). Edge gate design can facilitate smooth flow of metal and can therefore, minimize the formation of hot spots and eliminate porosity and holes defects. This design is well suited specifically for plate shape components having smaller thickness (approx. $<25 \mathrm{~mm}$ thick).
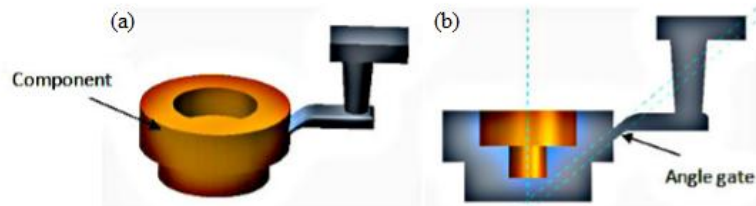

(c)
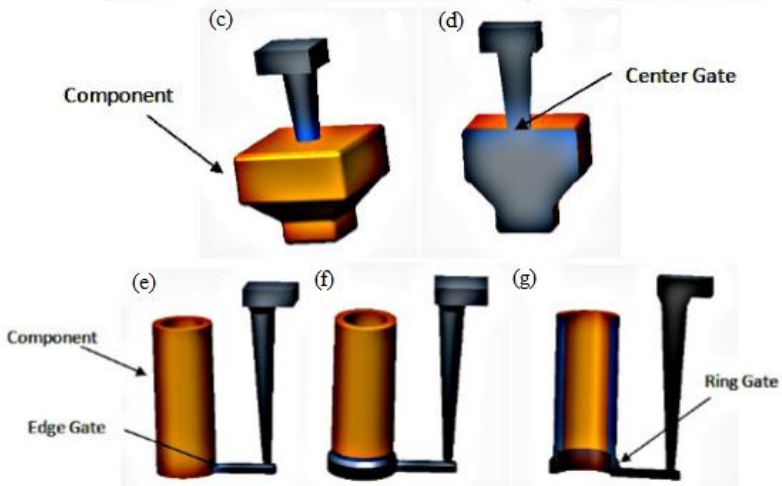

Fig. 9 Geometric structure of (a) Angle gate, (b) Cut section of Angle gate, (c) Centre gate, (d) Cut section of centre gate, (e) Edge gate, (f) Ring gate and (g) Cut section of ring gate.

\section{Ring gate}

It is suitable only for cylindrical components like pinion housing (pipe shape components). It goes into the selection of other types of gating systems for the cylindrical components which create flow marks, porosity and below hollows defects. Generally, the design and structure of the gating for manufacture are complicated. Fig. $9 \mathrm{f}$, demonstrates the usage of ring gate in circular components. In the case of edge gate selection, this component can direct the molten metal to hit the cylindrical wall and to

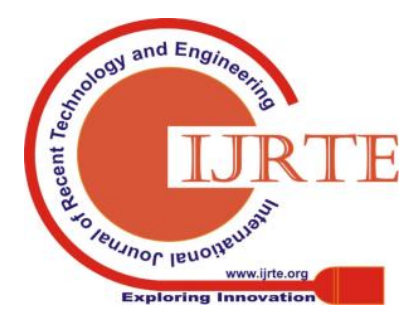


generate uneven filling resulting in the formation of air bubbles and micro porosity.

\section{E. Face gate}

This type of gating system is applicable for components with varying cross-sections machined at the face. The bottom faces of the face gate in these have contact with the top faces of the component. This cases the occurrence of uneven metal flow and a large gate area. Hence, most of the feeder designers do not prefer face gate unless the component design demands this type gating.

\section{CONCLUSION}

Even after the rapid growth of modern technologies, most of the traditional sand casting foundries still use trial and error processes for the feeding system, performing the process with various prototypes based on component design. Time consuming processes of this kind can lead to increase in running and material costs, production yield, and the percentage of defects in product and reduction in initial investment. Several simulation techniques are employed for overcoming these drawbacks and to locate, design, analyze, optimize and validate gating systems. Even then quality casting can get products free of pin holes, solid inclusions and discontinuity. The main aim of the feeding system can be achieved by facilitating smooth filling of the molten metal and minimization of turbulence through proper orientation of components, position of sprue runner and ingates. Change in section thickness, core size, number and location of gating are considered as critical factors influencing the casting quality of the components in various applications. There is no common design of the feeding system for use in all types of components. However, the basic idea relating to the selection of a good feeding system addressed in this article can be referred to for the future development of sand casting product.

\section{ACKNOWLEDGMENT}

The authors wish to thank the Department of Mechanical Engineering, Kalasalingam University for their permission to carry out the preparation and testing of the composites and wish to thank the Department of Science and Technology, India for funding through FIST Program SR/FST/ETI-275/2010.

\section{REFERENCES}

1. B. Ravi, "Metal casting: computer-aided design and analysis". PHI Learning Pvt. Ltd, 2005.

2. C. M. Choudhari, B. E. Narkhede, S. K. Mahajan, "Modeling and simulation with experimental validation of temperature distribution during solidification process in Sand casting". Int. J. Comput.S Appl. vol. 78(16), 2013, pp. 23-29.

3. M. S. Soiński, P. Kordas, K. Skurka, "Trends in the Production of Castings in the World and in Poland in the XXI Century". Archives of Foundry Engineering, vol. 16(2), 2016, pp. 5-10.

4. F. Pan, M. Yang, X. Chen, "A review on casting magnesium alloys: Modification of commercial alloys and development of new alloys". J Mater Sci Technol. vol. 32(12), 2016, pp. 1211-1221.

5. Schey, A. John, "Introduction to manufacturing processes". McGraw -Hill, New York, Vol, 2. 1987.

6. Y. N. Doctor, B. T. Patil, A. M. Darekar, 'Review of optimization aspects for casting processes". Int J Sci Res.vol. 4(3), 2015, pp. 2364-2368.

7. K. M. Daws, Z. I. AL-Dawood, S. H. AL-Kabi, "Selection of metal casting processes: A fuzzy approach”. JJMIE. Vol. 2(1), 2008.
8. C. Shi, G. Wu, L. Zhang, \& X. Zhang, "Al-5.5 Mg-1.5 Li-0.5 $\mathrm{Zn}-0.07 \mathrm{Sc}-0.07 \mathrm{Zr}$ alloy produced by gravity casting and heat treatment processing”. Mater. Manuf. Processes, vol. 33(8), 2018, pp. 891-897.

9. EPA, Office of Compliance Sector Notebook Project Profile of the Metal Casting Industry, 1988.

10. V. D. Shinde, B. Ravi, K. Narasimhan, "Solidification behaviour and mechanical properties of ductile iron castings with varying thickness". Int. J. Cast Met. Res, vol. 25(6), 2012, pp. 364-373.

11. V. Vasava, D. Joshi, "Simulation of shrinkage defect-A review". Int. J. Eng. Trens Technol, vol. 4(6), 2013, pp. 2361-2365.

12. M. A. A. Khan, A. K. Sheikh, "Simulation tools in enhancing metal casting productivity and quality: A review. Proceedings of the Institution of Mechanical Engineers", Part B: J. Eng. Manuf. Vol. 230(10), 2016, pp. 1799-1817.

13. A. Rai, S. K. Ganguly, "Web-based expert system for some defect in sand castings". Int. J. Adv. Engg. Res. 2015, pp. 171, 174.

14. S. .S. Jamkar, M. J. Deshmukh, N. A. Vidhate, "optimization of green sand casting process parameter by Taguchi method: a review". Int. J. Mech. Eng. vol. 4(1), 2014.

15. A. Kumaravadivel, U. Natarajan, C. Ilamparithi, "Determining the optimum green sand casting process parameters using Taguchi's method". Journal of the Chinese Institute of Industrial Engineers, vol 29(2), 2012, pp. 148-162.

16. H. Khandelwal, B. Ravi, "Effect of molding parameters on chemically bonded sand mold properties". J. Manuf. Process, vol. 22, 2016, pp. 127-133.

17. S. A. A. D. S. Jaju, "A review on optimization of gating system for reducing defect". 2014, pp. 93.

18. J. Campbell, "Complete casting handbook: metal casting processes, metallurgy, techniques and design". Butterworth-Heinemann, 2015.

19. S. Sikorski, G. W. Dieckhues, J. C. Sturm, "Systematic optimization of aluminum sand casting gating systems". Am. Foundry Soc. vol. 120, 2012, pp. 13-21.

20. K. H. Renukananda, B. Ravi, "Multi-gate systems in casting process comparative study of liquid metal and water flow". Mater. Manuf. Processes vol. 31(8), 2016, pp. 1091-1101.

21. S. L. Nimbulkar, R. S. Dalu, "Design optimization of gating and feeding system through simulation technique for sand casting of wear plate". Perspectives in Science, vol. 8, 2016, pp. 39-42.

22. M. V. Mohiuddin, S. F. Hussainy, A. Krishnaiah, P. Laxminarayana, "Experimental investigation to produce thin-walled sand casting using combination of casting simulation and additive manufacturing techniques". The Int J Adv Manuf Technol. vol. 90(9-12), 2017, pp. 3147-3157.

23. A. Modaresi, A. Safikhani, A. M. S. Noohi, N. Hamidnezhad, S. M Maki, "Gating System Design and Simulation of Gray Iron Casting to Eliminate Oxide Layers Caused by Turbulence". Int. J. Metalcast vol. 11(2), 2017, pp. 328-339.

24. H. Iqbal, A. K. Sheikh, A. Al-Yousef, M. Younas, "Mold design optimization for sand casting of complex geometries using advance simulation tools". Mater. Manuf. Processes, vol. 27(7), 2012, pp. 775-785.

25. C. M. Choudhari, B. E. Narkhede, \& S. K. Mahajan, "Casting design and simulation of cover plate using AutoCAST-X software for defect minimization with experimental validation". Procedia Materials Science, vol. 6, 2014, pp. 786-797.

26. A. Kermanpur, S. Mahmoudi, A. Hajipour, A. "Numerical simulation of metal flow and solidification in the multi-cavity casting moulds of automotive components". J. Mater. Process. Technol. vol. 206(1-3), 2008, pp. 62-68.

27. F. G. Mi, X. Y. Liu, K. F. Wang, H. Z. Fu, "Application of numerical simulation technique to casting process of valve block". J. Iron Steel Res. Int. vol. 16(4), 2009, pp. 12-17.

28. I. Hahn, J. C. Sturm, "Autonomous optimization of casting processes and designs. Proceedings of the 69th World Foundry Congress", Hangzhou, China, 2010, pp.16-20.

29. K. Deb, A. R. Reddy, G. Singh, "Optimal scheduling of casting sequence using genetic algorithms". Mater. Manuf. Processes, vol. 18(3), 2003, pp. 409-432.

30. N. Ducic, Z. Cojbasic, S. Manasijevic, R. Radisa, R. Slavkovic, I. Milicevic, "Optimization of the Gating System for Sand Casting Using Genetic Algorithm". Int. J. Metalcast, vol. 11(2), 2017, pp 255-265. 
31. R. K. Halappa, U. Chheda, R. Bhallamudi, "Flow Through Multi-Gate Gating System: Experimental and Simulation Studies". In ASME International Mechanical Engineering Congress and Exposition, 2013 pp. 046.

32. F. Y. Hsu, M. R. Jolly, J. Campbell, "A multiple-gate runner system for gravity casting". J. Mater. Process Tech. vol. 209(17), 2009 pp. 5736-5750.

33. H. Zhao, I. Ohnaka, J. Zhu, "Modeling of mold filling of Al gravity casting and validation with X-ray in-situ observation". Appl. Math Model, vol. 32(2), 2008, pp. 185-194.

34. M. Sutaria, B. Ravi, "Computation of casting solidification feed-paths using gradient vector method with various boundary conditions". The Int. J. Adv. Manuf. Tech vol. 75(1-4), 2014, pp. 209-223.

35. L. Zhang, F. Belblidia, H. M. Davies, N. P. Lavery, S. G. Brown, D. Davies, "Optimizing gate location to reduce metal wastage: $\mathrm{Co}-\mathrm{Cr}-\mathrm{W}$ alloy filling simulation". J. Mater. Process. Technol. vol. 240, 2017, pp. $249-254$.

36. S. M. H. Mirbagheri, M. Shrinparvar, H. Ashory, P. Davami, "Simulation of surface roughness on the flow pattern in the casting process". Materials \& design, vol. 25(8), 2004, pp. 655-661.

37. G. Mageshwaran, S. R. Polisetti, J. Jeevahan, G. B. Joseph, "Enhancement of uniform temperature distribution during casting solidification by methoding process". Int. J. Ambient Energy vol. 38(8), 2017, pp. 774-780.

38. D. Joshi, B. Ravi, "Classification and simulation based design of 3D junctions in castings". Transactions of American Foundry Society, vol 117,2009 , pp. 7-22.

39. L. Zhang, W. Tan, H. Hu, "Determination of the heat transfer coefficient at the metal-sand mold interface of lost foam casting process". Heat and Mass Transfer, vol. 52(6), 2016, pp. 1131-1138.

40. S. Yao, T. Wang, L. Sui, Q. Tong, Y. Jiao, "Effects of dynamic gate pouring on casting's filling and feeding capacity". Mater. Manuf. Processes vol. 32(5), 2017, pp. 501-506.

41. J. Li, R, Chen, Y. Ma, W. Ke, "Characterization and prediction of microporosity defect in sand cast WE54 alloy castings". J. Mater. Sci. Technol. vol. 30(10), 2014, pp. 991-997.

42. Y. Fu, H. Wang, C. Zhang, H. Hao, "Numerical simulation and experimental investigation of a thin-wall magnesium alloy casting based on a rapid prototyping core making method". Int. J. Cast. Metal Res. Vol. 31(1), 2018, pp. 37-46.

43. G. A. Hodbe, B. R. Shinde, "Design And Simulation Of LM 25 Sand Casting For Defect Minimization”. Materials Today: Proceedings, vol. 5(2), 2018, pp. 4489-4497.

44. M. Sutaria, V. H. Gada, A. Sharma, B. Ravi, "Computation of feed-paths for casting solidification using level-set-method". J. Mater Process Tech, vol. 212(6), 2012, pp. 1236-1249

\section{AUTHORS PROFILE}

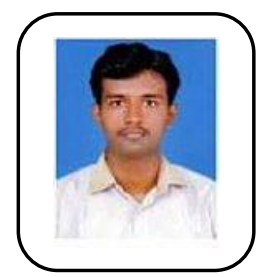

I.Rakumar, received the Degree in mechanical engineering and master degee in CADCAM, He is a Associate Professor of mechanical engineering, Kalasalinagm Academy of Research and Education, Krishnankoil, Virudhunagar, Tamil Nadu, India. research areas of interest metal casting.

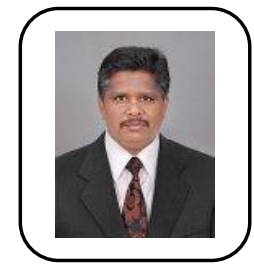

N.Rajini, received the Degree in mechanical engineering and master degee in Engineering Design, $\mathrm{He}$ is a Professor of mechanical engineering, Kalasalinagm Academy of Research and Education, Krishnankoil, Virudhunagar, Tamil Nadu, India. research areas of interest are polymer Nano composites, He has published 87 papers in various international journals. 